\title{
Research Paper \\ Antimicrobial Effect of Zataria Essential Oil on the Skin Bacteria in Wistar Rats
}

\author{
Soheila Faramarz Isfahanian ${ }^{1} \odot{ }^{*}$ Maryam Sadrnia $^{1} \odot$ Sima Nasri $^{1}$, Hamid Sobhanian $^{1}$
}

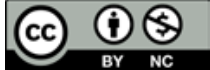

Article Info:

Received: 27 Sep 2019

Accepted: 13 Feb 2020

Available Online: 01 Jun 2020

Keywords:

Zataria essential

oil, Cosmetics, Skin

bacteria

\section{ABSTRACT}

Objective Zataria is one of the native plants of Iran which is widely used for the treatment of diseases among Iranians. In this study, we investigated the antimicrobial effects of Zataria essential oil on the skin bacteria in rats.

Methods Bacterial strains were isolated from the skin of 6 wistar rats and the antimicrobial effects of Zataria essential oil were evaluated by disk diffusion and microbroth dilution methods. In-vivo tests were performed to evaluate the antimicrobial effect of the essential oil by microbial culture as well as allergy tests on the skin of experimental rats compared to controls.

Results Three bacterial strains were isolated from the skin of rats identified as Staphylococcus aureus, Corynebacterium and Staphylococcus epidermidis. Minimum Growth Inhibitory Concentration (MIC) and Minimum Bactericidal Concentration (MBC) for the two strains of Staphylococcus aureus and Corynebacterium were obtained 0.39 and $0.78 \mathrm{mg} / \mathrm{ml}$, while for Staphylococcus epidermidis, they were 0.195 and $0.39 \mathrm{mg} / \mathrm{ml}$, respectively. In-vivo test results showed the antibacterial effect of the essential oil on the skin bacteria and no inflammatory effects were observed under the allergy test.

Conclusion Zataria essential oil has antimicrobial effects on the skin infections in lower concentrations. The use of this essential oil as an antiseptic and preservative in cosmetics is recommended instead of chemical preservatives that generally have skin side effects.

\section{Extended Abstract}

\section{Introduction}

I

n cosmetics, preservatives such as parabens, benzyl alcohol, salicylic acid, alcohol sterols and formaldehyde are used to inhibit the growth of bacteria and fungi. Microbial contamination may be present in non-standard cosmetics from the beginning and may be transmitted to the consumer during production and pack- aging or during consumption and improper storage. The percentage of preservatives in the final product is usually between $0.01 \%$ and $5 \%$. These chemicals can cause glandular and hormonal disorders. With the continuation of consumption, the possibility of their carcinogenicity also increases. Recent studies have emphasized the low efficacy of these substances. In this regard, the investigation for herbal ingredients as a preservative in cosmetics has recently become a priority. Zataria is one of the native plants of Iran and its consumption for treatment of diseases is common among Iranians. In this study, the effect of Zataria

\section{* Corresponding Author:}

Maryam Sadrnia, PhD.

Address: Department of Biology, PayameNoor University, Tehran, Iran

Tel: +98 (918) 8608302

E-mail: msadrnia@yahoo.com 
essential oil on skin bacteria was evaluated to examine its applicability to cosmetics.

\section{Materials and Methods}

In this study, 6 adult Wistar rats were used. The rats were first temporarily anesthetized by chloroform and then were given an intraperitoneal injection of Ketamine/Xylazine (2:1 dose ratio) to increase the anesthesia time proportional to their weight. The hair on the back of the rats was shaved and disinfected after anesthesia. This place was contaminated with three isolated bacteria including corynebacterium, staphylococcus epidermidis and staphylococcus aureus using a sterile swab with $0.5 \mathrm{McF}$ arland standard concentration. In the three tested rats, 120 minutes after the skin was impregnated with the three bacteria, the essential oil with Minimum Bactericidal Concentration (MBC) was sprayed to the microbial site. After 60 minutes, the spraying was repeated. At the end, 60 minutes after the second time of spraying, the skin of experimental rats impregnated with the microbe and treated with the essential oil, was sampled and cultured on the nutrient agar medium. Then, the colonies that had grown in this medium were laminated and compared with the lams of the previous stage. Moreover, after 30, 60 and 90 minutes of spraying the essential oil on the skin of rats in the experimental group, their skin reactions were examined.

Bacterial strains were isolated from the skin and the antimicrobial effects of Zataria essential oil were evaluated by disc diffusion and microbroth dilution methods. For isolation and identification of skin bacteria, the back of the rat's hand was washed with soap and dried. A sterile swab moistened with distilled water was applied to the back of the hand, and grass cultivation was performed on the Mueller-Hinton Agar. By conventional microbiological methods including cultivation in different mediums and colonial and staining studies, isolated bacteria were identified. For disk diffusion method, blank discs were placed at appropriate distances on the cultured medium and $20 \mu$ of diluted Zataria essential oil was poured on each disc.

After 24 hours of incubation, the diameters of the zone of inhibitions were measured. Minimum Inhibitory Concentration (MIC) was determined in sterile 96-well microplates. First, $100 \mu \mathrm{l}$ of culture media containing bacteria were poured into the all wells. Then, $100 \mu \mathrm{l}$ of antimicrobial solution was added to the first well. From the second to the third well until the tenth well, $100 \mu$ l of solution was transferred each time. Next, $100 \mu \mathrm{l}$ of pure microbial suspension was added to the 11 th well and $100 \mu$ of the antimicrobial solution to the 12th well. The turbidity which indicates the growth or non-growth of the bacterium, was measured by a microplate (Synergy HTX, BioTek Instruments, China) at a wavelength of $545 \mathrm{~nm}$ for all three bacteria. The concentration of the last non-growth well was recorded as MIC. The well concentrations were arranged in descending order, from 50 to $0.097 \mu \mathrm{l} / \mathrm{ml}$. In-Vivo experiments were performed to evaluate the antimicrobial properties of microbial culture and its allergenicity on the skin of 6 rats compared with control mice.

\section{Results}

Three bacteria isolated from the skin were identified as staphylococcus aureus, corynebacterium, and staphylococcus epidermidis. The MIC and MBC for the two strains of Staphylococcus aureus and Corynebacterium were obtained 0.39 and $0.78 \mathrm{mg} / \mathrm{ml}$, respectively and for Staphylococcus epidermidis, they were 0.195 and $0.39 \mathrm{mg} / \mathrm{ml}$. The results of the MicroBroth dilution showed that Zataria essential oil in very low concentrations was able to inhibit the growth of all three bacteria. It should be noted that Staphylococcus aureus and Corynebacterium had higher MIC than Staphylococcus epidermidis. This means that the essential oil has inhibited the growth of Staphylococcus epidermidis with greater strength and speed. In-vivo test results showed the antibacterial effect of Zataria essential oil on the skin of rats, and no allergic effects were observed in the allergy assessment. In cultures of samples taken from the skin of control rats, all three bacteria grew during culture, but in the cultures of samples taken from the skin of experimental rats, none of them grew, which indicates that they were killed by Zataria essential oil. After 30,60 and 90 minutes of treatment with Zataria essential oil, no allergic reaction caused by sensitivity to this essential oil was observed in the skin of experimental rats.

\section{Conclusion}

The Zataria essential oil in low concentrations has longterm antimicrobial effects on the infectious bacteria.

\section{Ethical Considerations}

\section{Compliance with ethical guidelines}

This study was conducted with the tracking code of: 2545562 and registered in the national committee of ethics in medical researchs: (Code: IR.PNU.REC.1396,6).

\section{Funding}

The present paper was extracted from the master thesis of the first author Department of Biology, PayameNoor University. 


\section{Authors' contributions}

Conceptualization: Maryam Sadrnia \& Sima Nasri; Methodology: Maryam Sadrnia, Sima Nasri, Hamid Sobhanian; Software: Maryam Sadrnia; Validation: Maryam Sadrnia, Sima Nasri ,Hamid Sobhanian; Formal Analysis: Soheila Faramarz Isfahanian, Maryam Sadrnia; Investigation: Soheila Faramarz Isfahanian, Maryam Sadrnia; Resources: Sima Nasri ,Hamid Sobhanian; Data Curation: All Authors; Writing - Original Draft Preparation: Soheila Faramarz Isfahanian \& Maryam Sadrnia; Writing - Review \& Editing: All Authors; Visualization: Maryam Sadrnia; Supervision: Maryam Sadrnia; Project Administration: Maryam Sadrnia, Sima Nasri, Hamid Sobhanian; Funding Acquisition: Maryam Sadrnia, Sima Nasri, Hamid Sobhanian.

Conflicts of interest

The authors declared no conflict of interest.

Acknowledgements

The authors would like to thank the Research Vice Chancellor of Payame Noor University for their cooperation in conducting this research. 
ارزيابى خواص ضدميكروبى اسانس آويشن بر باكترى هاى يوست جهت استفاده در مواد آرايشى

\author{
سهيلا فرامرز اصفهانيان' ف، "مريم صدرنيا' . سيما نصرى'، حميد سبحانيان'
}

1. بروه زيستشناسى، دانشعاه بيام نور، تهران، ايران.

\begin{abstract}
سيكيد
هدف آويشن يكى از كياهان بومى ايران است كه مصرف آن جهت درمان كياهى بيمارىهاء در بين ايرانيان رواج دارد. در اين تحقيق اثرات

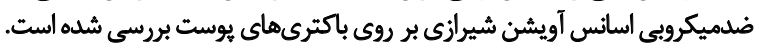

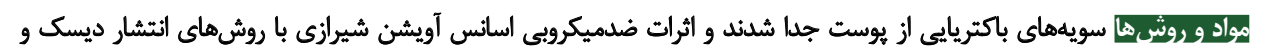

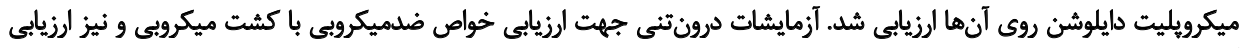

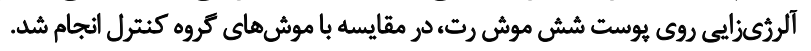

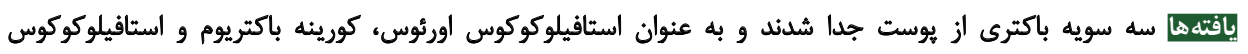

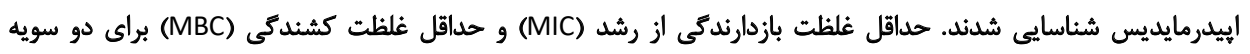

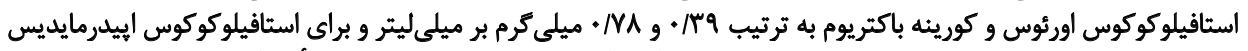

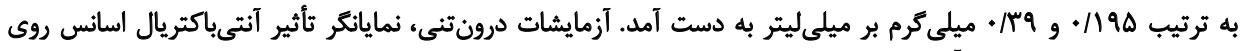

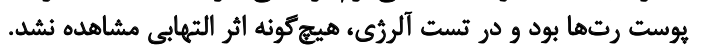

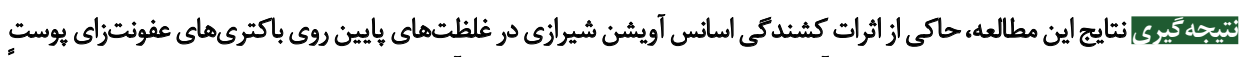

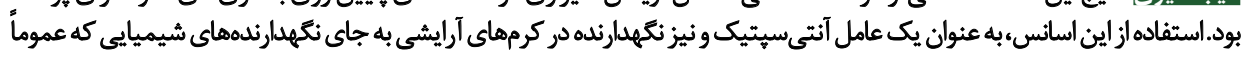

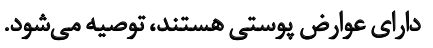

اطلاعات مقاله:

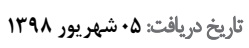

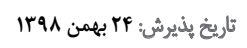
تاريخ انتشار: rا ترداد

كليدوازٔهها: اسائس آويشن، مواد آرايشى، باكترىهاى آران

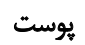

حاصل از اسانسي آويشن در ترميم 9 بهببود برخى بيمارىهاى

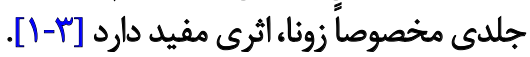

dato

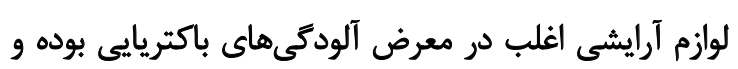

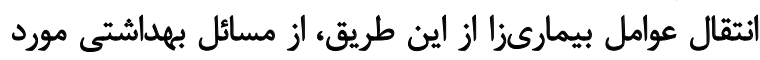

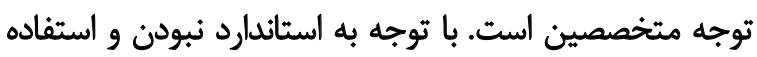

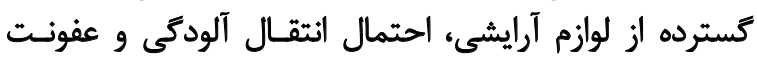

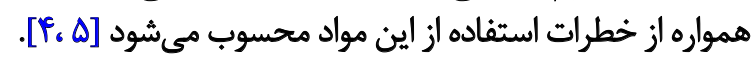

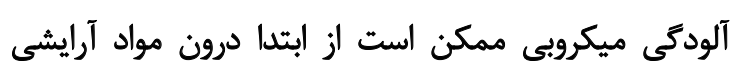

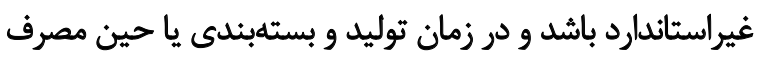

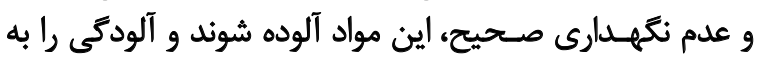

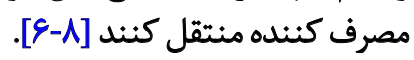

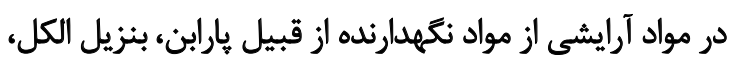

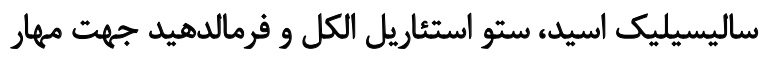

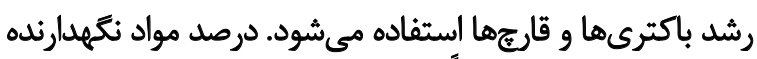

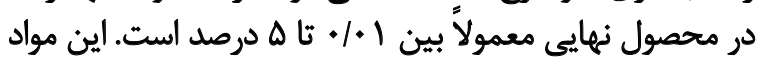

باظهور عوارض جانبى آنتىبيوتيكهاو بروز يديده مقاومت دارويى

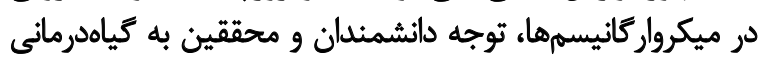

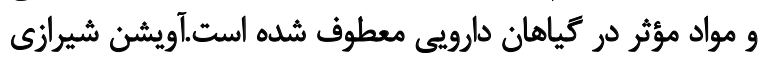

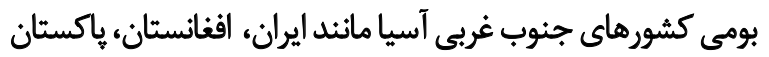

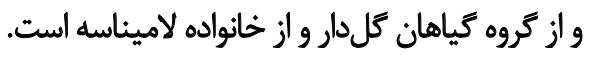

تركيبات اصلى كياه خشك آويشن شيرازى، تيمول و وارئ

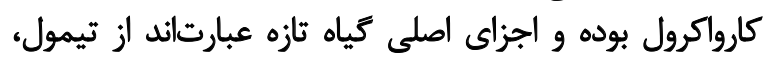

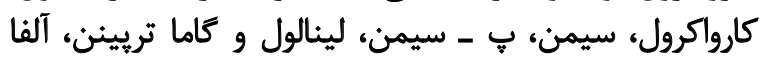

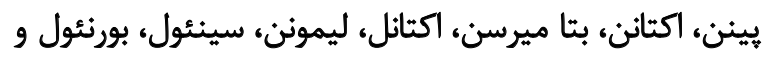

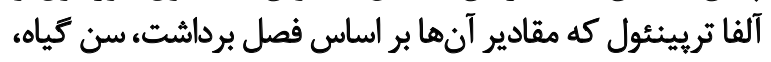

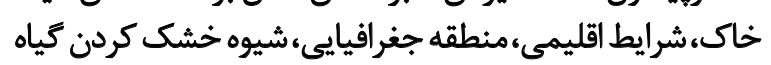

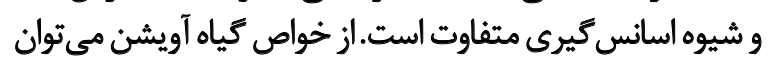

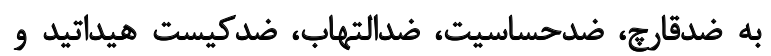

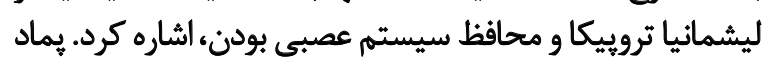




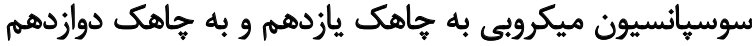

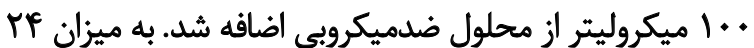

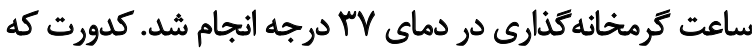

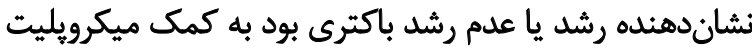

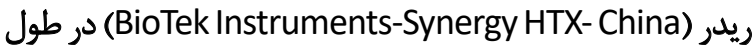
موج هFA نانومتر براى هر سه باكترى انجام شد. غلظت آخرين

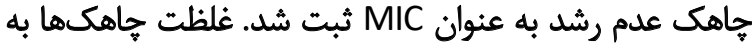

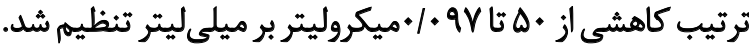

\section{تعيين حداقل غلظت كشئدكى}

براى تعيين حداقل غلظت كشندكى باكترىها'، يس از تعيين

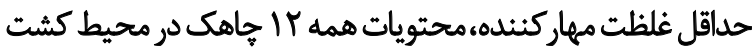

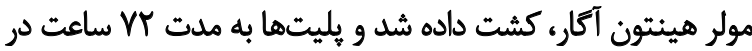

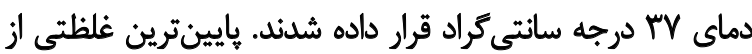

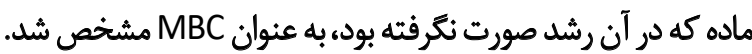

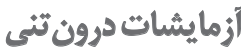

در اين تحقيق جمعاً از شش موش رت ويستار بالغ استفاده

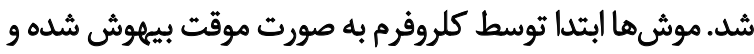

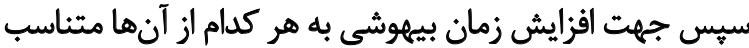

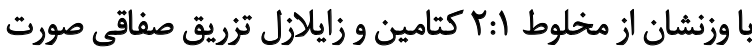

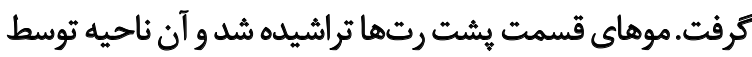

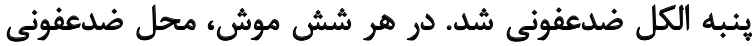

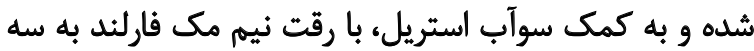

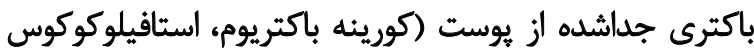

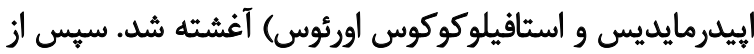

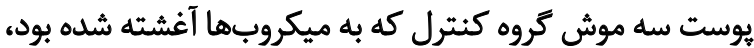

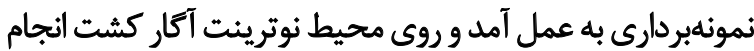

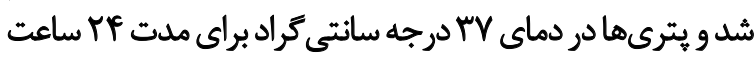

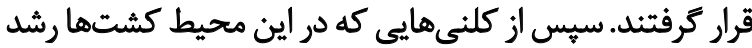

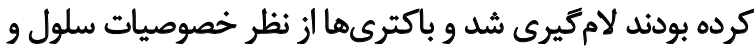

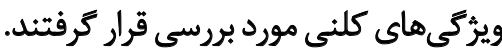

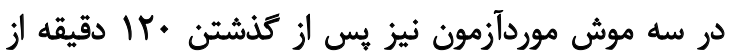

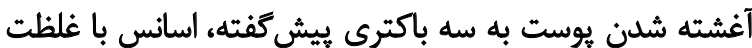

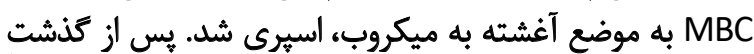

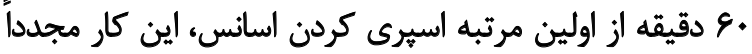

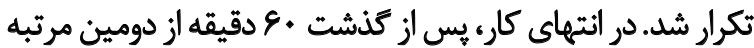

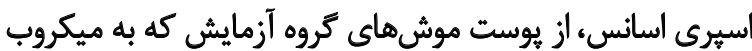

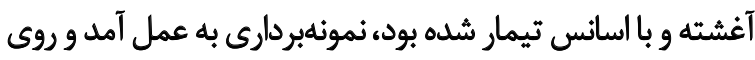

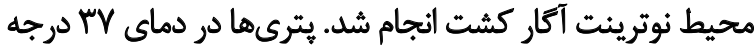

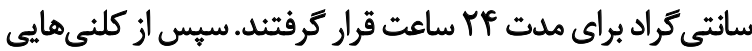

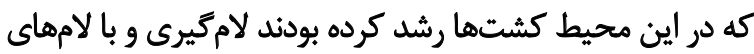

2. Minimum Bactericidal Concentration (MBC)
شيميايى مي توانئد باعث اختلالات غددى و هورمونى شوند.

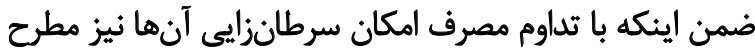

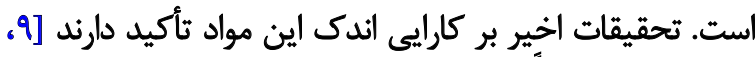

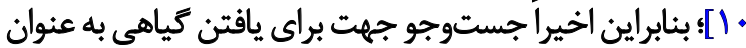

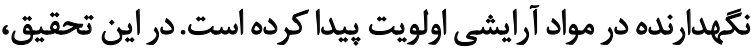

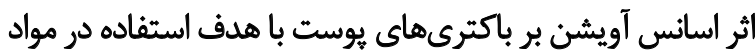
آرايشى مورد ارزيابى قرار كرفته است بانت

مواد وروشه نها

$$
\text { تجبيه كياه و اسانس كيرى }
$$

كياه آويشن شيرازى از مزرعه كياهان دارويى تهيه شد. كياه

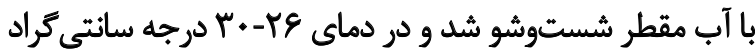

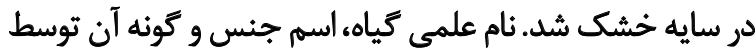

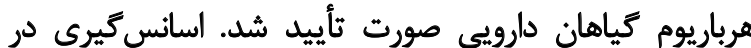

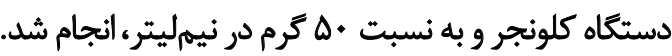

\section{جداسازي و شناسايي باكترى هاي يوست}

يشت دست با صابون شسته و خشك شد. يك سوآب استريل

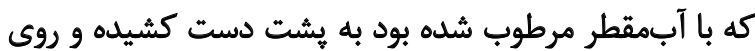

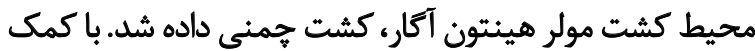
روشهايي معمول شناسى ماكروسكويى و ميكروسكويى شارئ شامل

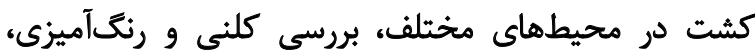

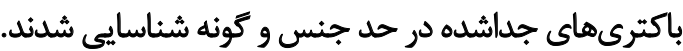

$$
\text { روش اتثشار ديسك }
$$

سويانسيون باكترى تازه باغلظت 1+1||x|| معادل رقت نيم

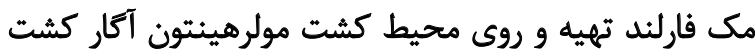

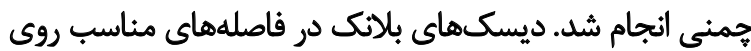

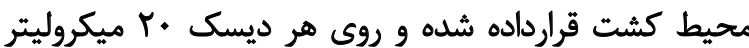

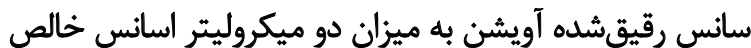

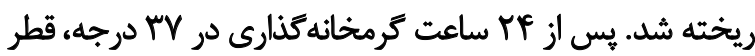
هالههاى اطراف ديسكها اندازهكيرى شد. تعيين حداقل غُلظت مهار كئنده

با بمك روش ميكرويليت دايلوشن، حداقل غلظت مهاركنيده'

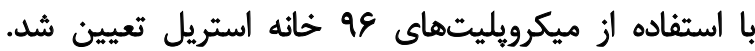

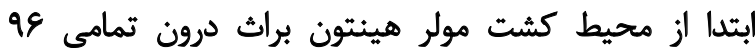

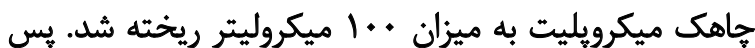

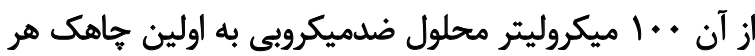

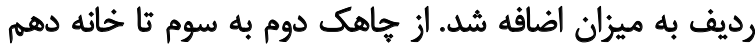

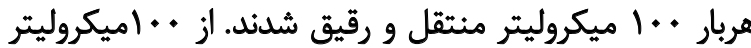

1. Minimum Inhibitory Concentration (MIC) 
مىشود و اكر باكترى را در اين غلظت از اسانس، در محيط مقدي

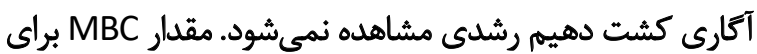

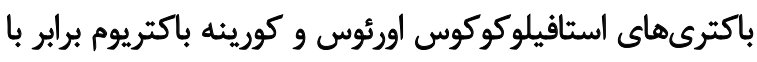

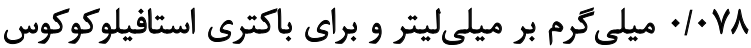

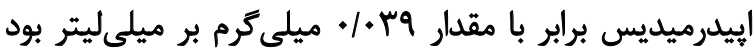

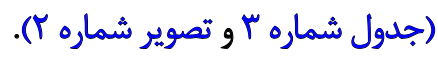

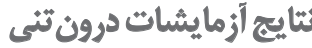

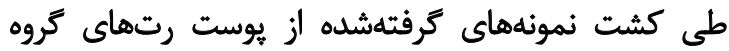

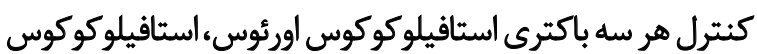
إييدرميديس و كورينه باكتريوم رشد كردئن

در كشتهاي انجامشده از نمونههاي كرفتهشده از يوست

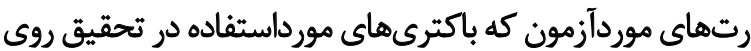

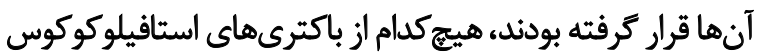

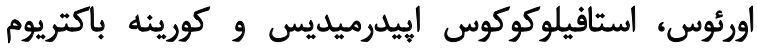

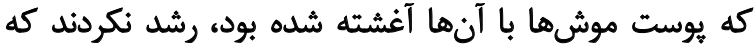

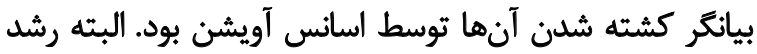

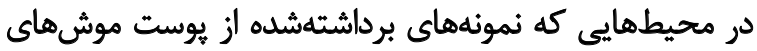

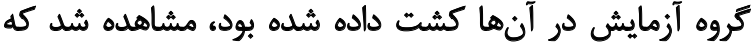

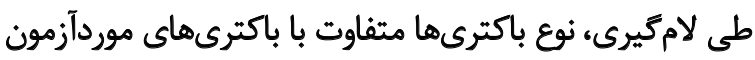

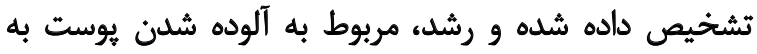

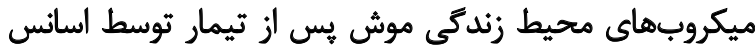

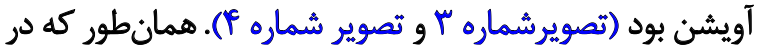

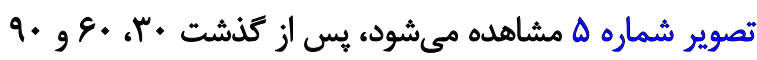

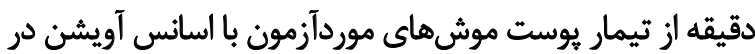

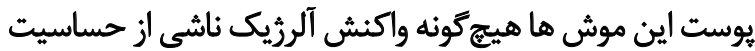

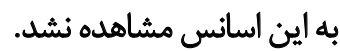

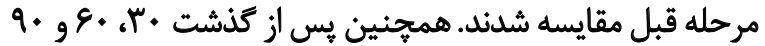

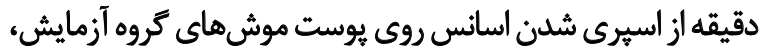
واكنشهاى يوستى اين سه موش مورد بررسى قرار گرقفت.

يافتهها

$$
\text { شناسائ جدايهها }
$$

باكترىهاى جداشده از يوست تحت عناوين استافيلوكوكوس الييدرمايديس، استافيلوكوكوس اورئوس و كورينه باكتريوم شناسايى شدند.

\section{ثتايج أزمايشات برونتنى}

نتايج اثر اسانس آويشن بر باكترىهاى جداشده از يوست در

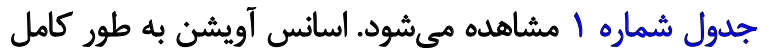

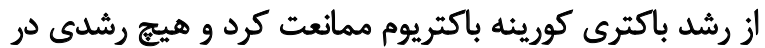

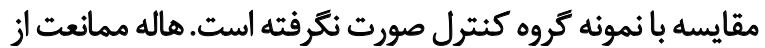

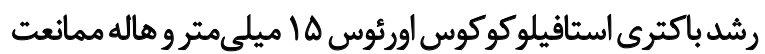
از رشد باكترى استافيلوكوكوس اييدرميديس با ا ميلىمتر بودي

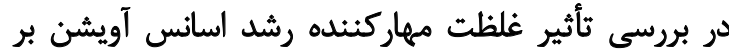

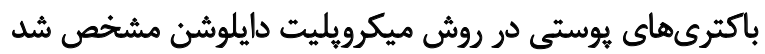

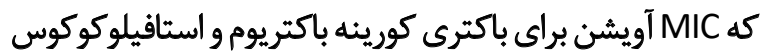

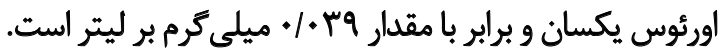
مقدار MIC براى باكترى استافيلوكوكوس اييدرميديس نيز برابر

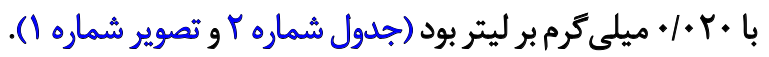
حداقل غلظت كشندگى (MBC)، غلظتى از اسانس است كه

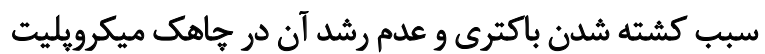

جدول ا. بررسى اثر اسانس كياه آويشن با روش انتشار ديسك

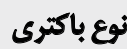

Staphylococcus epidemidis

Staphylococcus aureus

Corynebacterium spp.

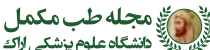

\begin{tabular}{|c|c|c|}
\hline 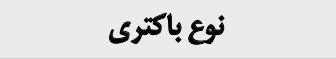 & رقت اسنس & غلظت اسانس (ميكروّرم بر ميلىليتر) \\
\hline Staphylococcus epidermidis & V/AIT &.$/ 190$ \\
\hline Staphylococcus aureus & I/TAP &.$/ 4 q$ \\
\hline Corynebacterium spp. & $1 / T \Delta E$ & $+/ \% q$ \\
\hline
\end{tabular}

جدول r. بررسي حداقل غلظت بازدارندكى رشد به روش ميكرويليت دايلوشن بر باكترىهاى بوست

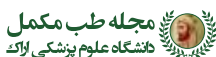


جدول ٪. بررسى حداقل غلظت كشندكى اسانس به روش ميكرويليت دايلوشن بر باكترىهاى يوست

\begin{tabular}{|c|c|c|c|}
\hline غلظت اسانس (ميكروكرم بر ميلىليتر) & رقت اسانس & جاهك & نوع باكترى \\
\hline$+/ 4 q$ & VTAS & $\wedge$ & Staphylococcus epidermidis \\
\hline . /VAI & VIFA & $\checkmark$ & Staphylococcus aureus \\
\hline . $/ \mathrm{VAI}$ & V/rA & $\checkmark$ & Corynebacterium spp. \\
\hline
\end{tabular}

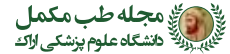

اسانس آويشن MBC

0.09

0.08

0.07

0.06

0.05

0.04

0.03

0.02

0.01

- Staphylococcus epidemidis $\amalg$ Staphylococcus aureus $\amalg$ Corynebacterium SPP.

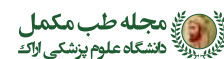

تصوير r. مقايسه MBC سه نمونه باكترى

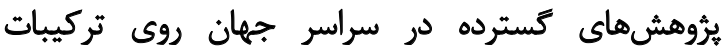

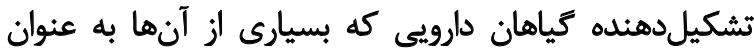

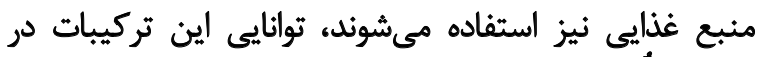

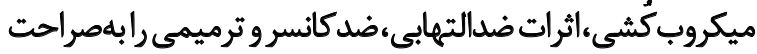

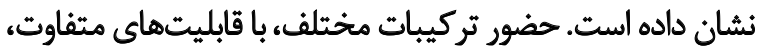

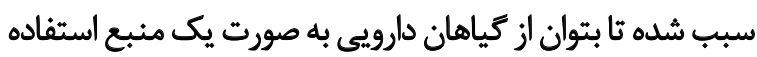

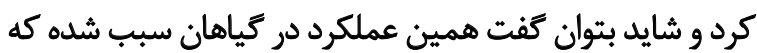

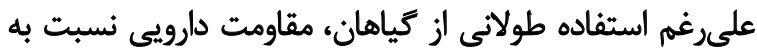

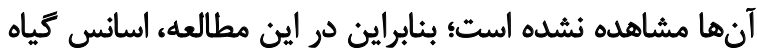

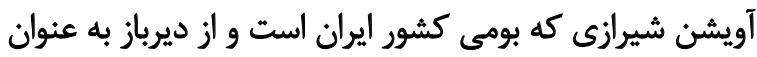

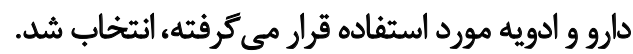

همجنين بايد توجه داشت كه امروزه رقابت جهانى در تمامى

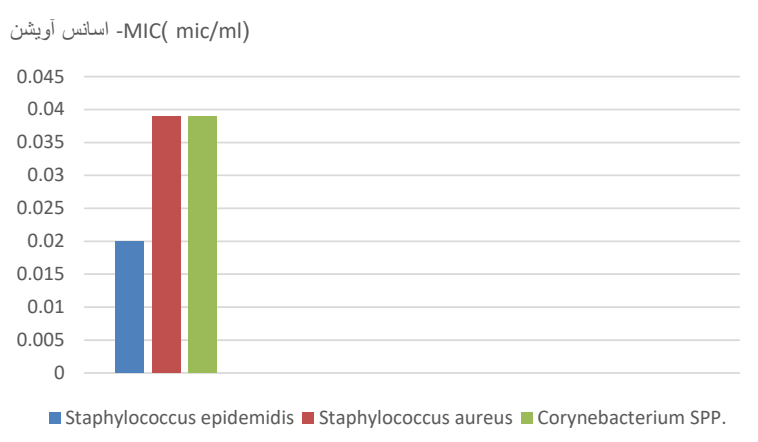

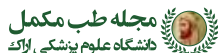

تصوير ا. مقايسه MIC در سه باكترى موردمطالعه ث

با توجه به مضرات نكمهارندههاى شيميايى در مواد آرايشى،

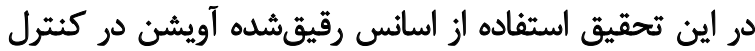

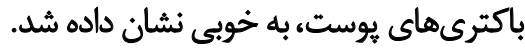

باكترىهاى ساكن يوست در صورت مناسب بودن شرايط

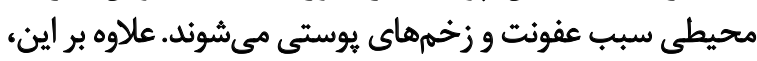

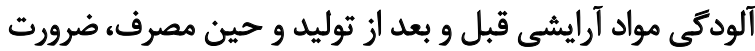

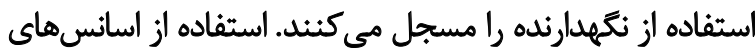

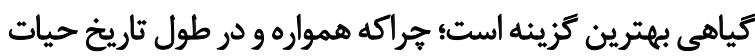
انسان، كياهان بهترين منابع غذا و دارو بودهاند [11].

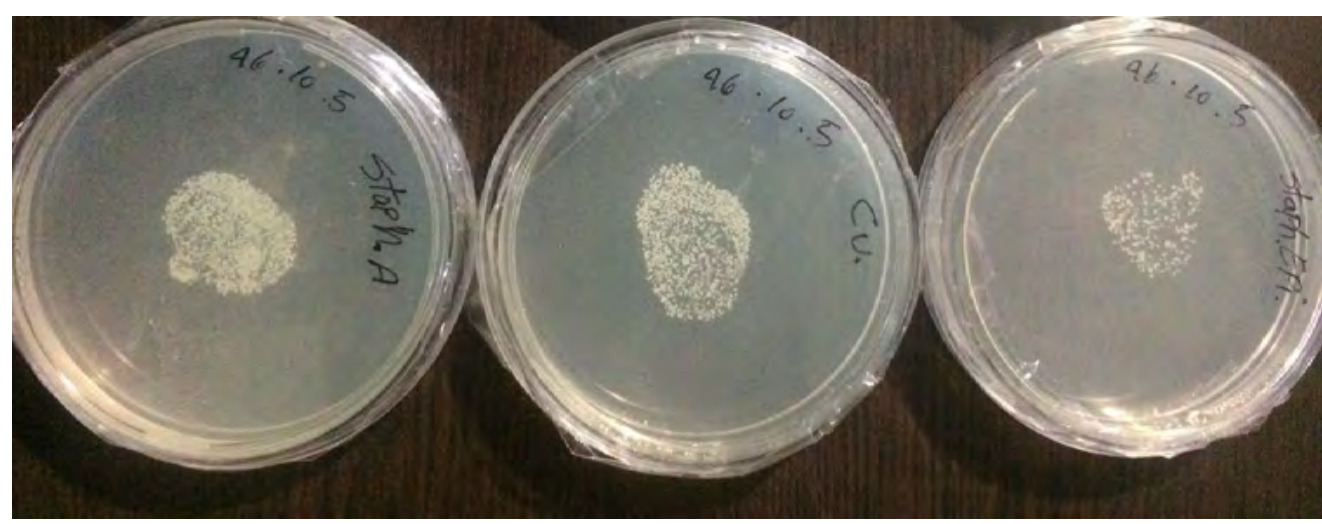




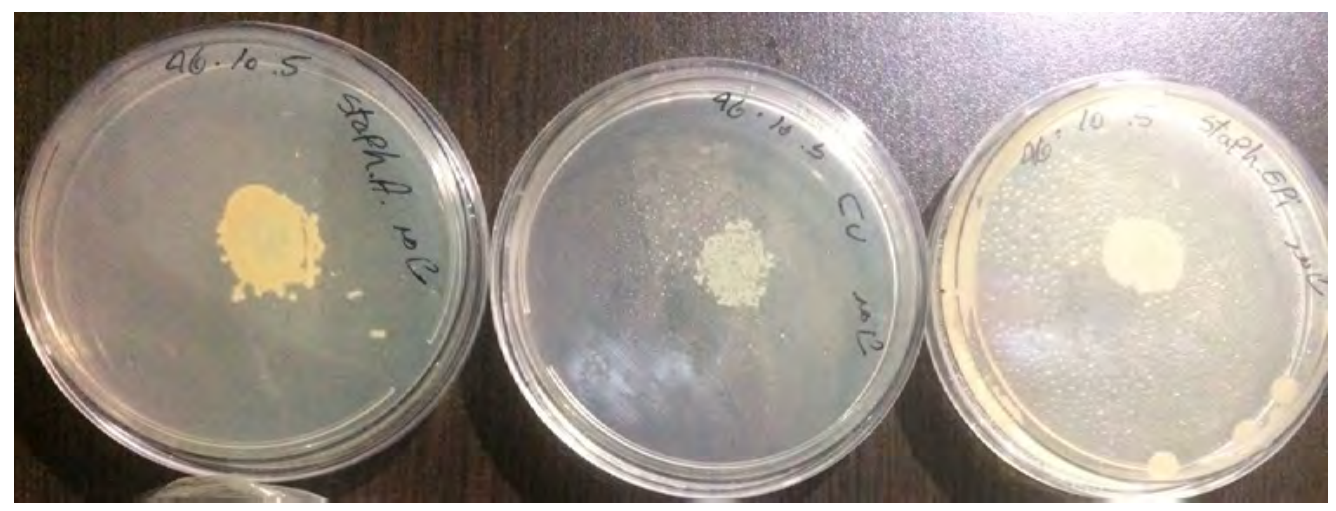

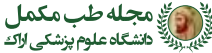

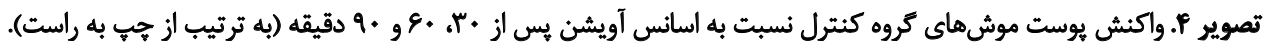

بيمارىها، شناسايى گياهان مؤثر در بيشخيرى أز بروز بيمارىها،

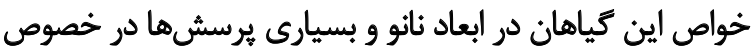

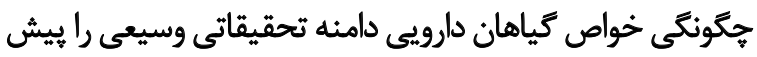

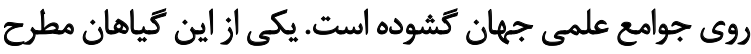

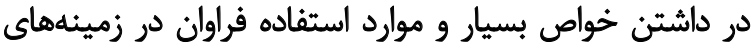

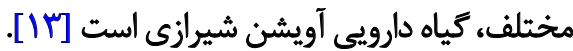
مصحفى و همكاران، يُروهشى گَسترده در زمينه اثرات

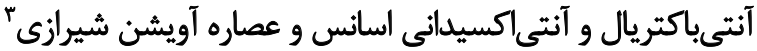

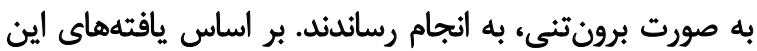

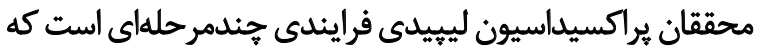

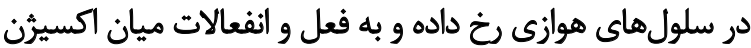

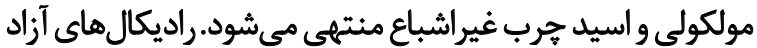

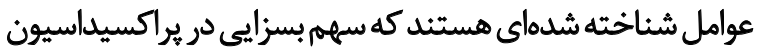

3. Zataria multiflora
عرصههاى علمى، صنعتى، اقتصادى، يزشكى به شكلى بـ بسيار

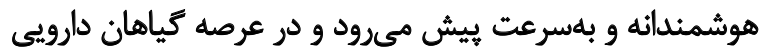

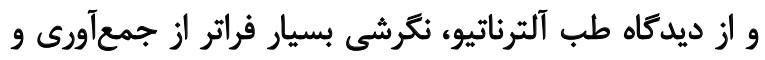

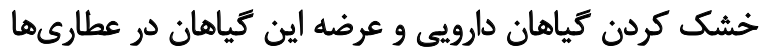

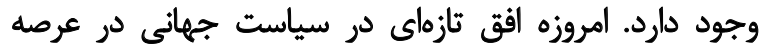

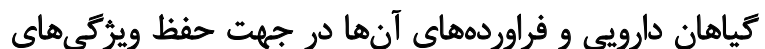

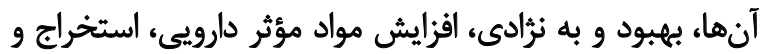

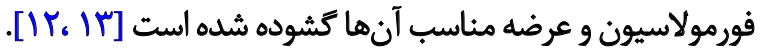
در زمينه كياهان دارويى و استفاده بهينه از آنها، به جز شرايط

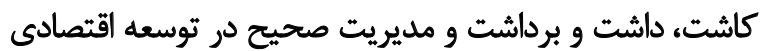

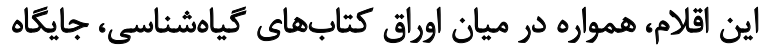

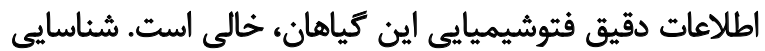

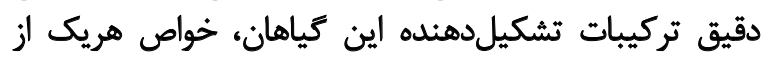

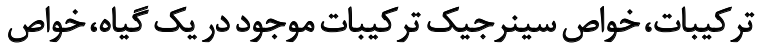

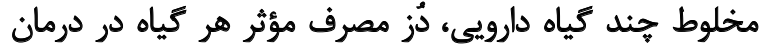

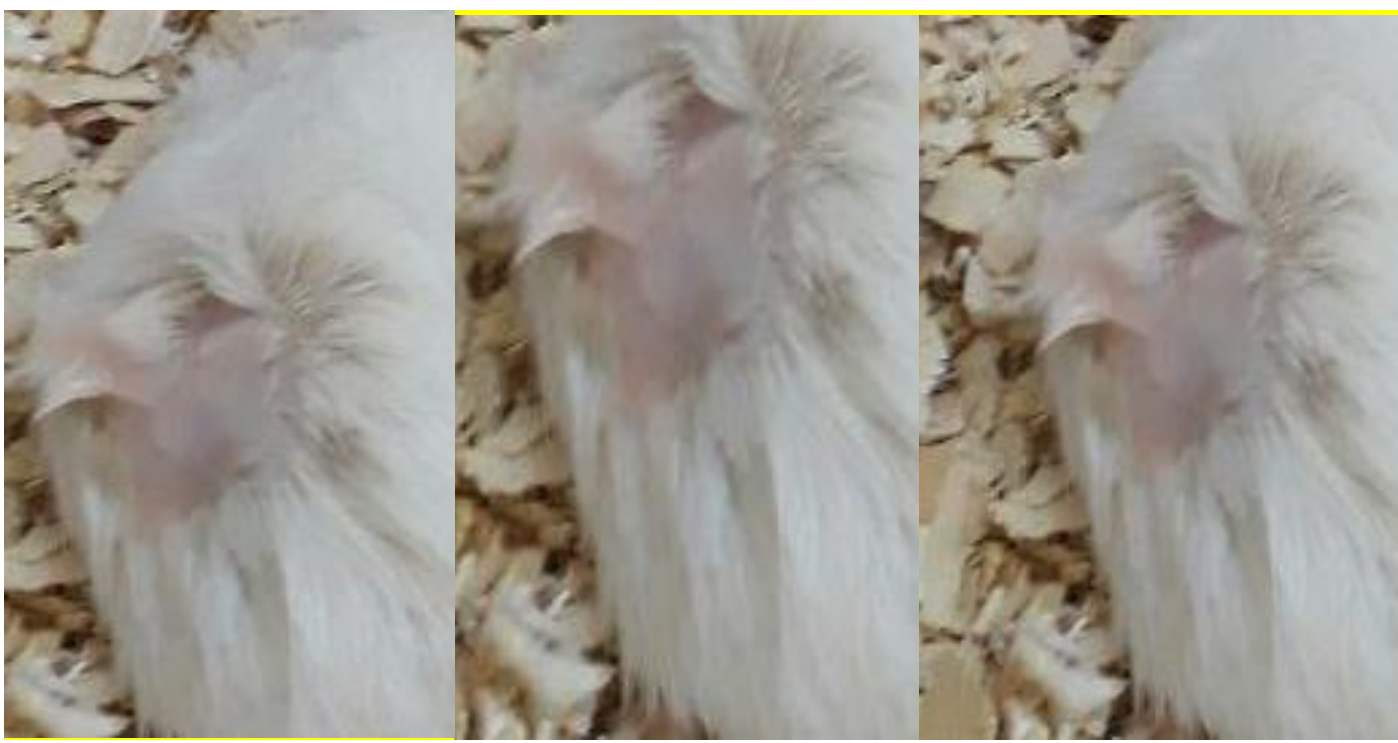

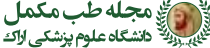

تصوير ه. واكنش يوست موش نسبت به اسائس آويشن يس از •لا، •و .9 دقيقه (به ترتيب از جبي به راست) 
Streptococcus اسانسهاى كياهان بومى ايران روى باكترى (عامل بيمارى استريتوكوكوزيس، مشترى بئ بين آبزيان

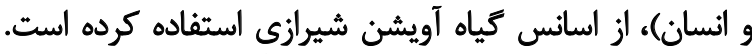

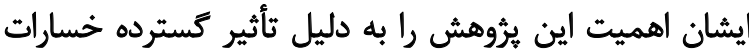

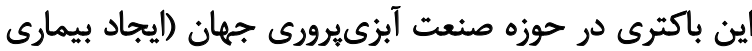

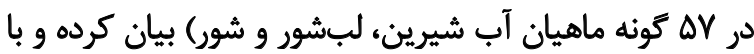
خاطرنشان كردن عوارض بيمارى استريتوكوكوزيس در انسي انسانهان

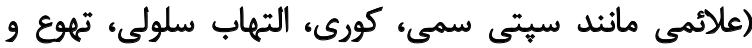

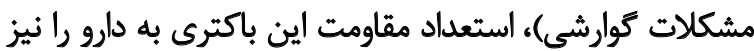

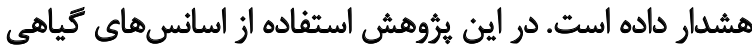

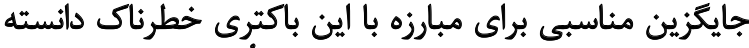

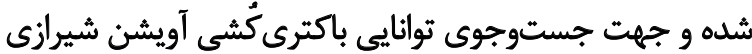

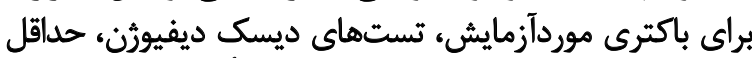

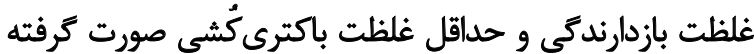

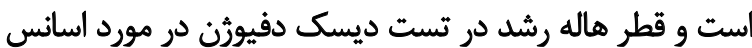

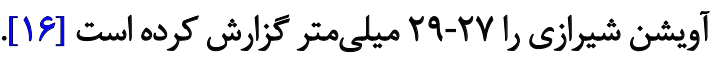

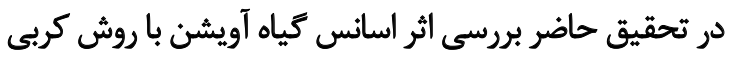

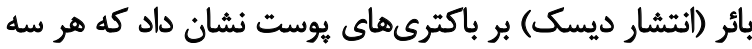

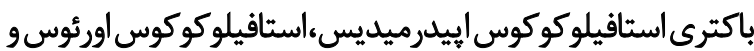

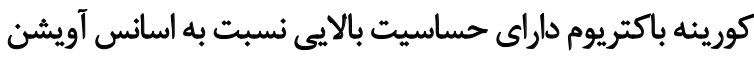

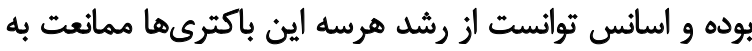

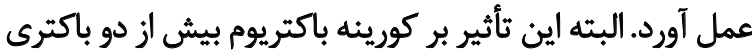

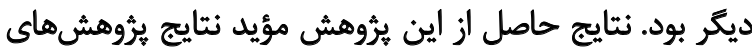
بيشين در زمينههاى مشترك با اين مطالعه بوده است.

جبلى جوان، در يرؤهشى به بررسى تأثير اسانسهاى زنيان

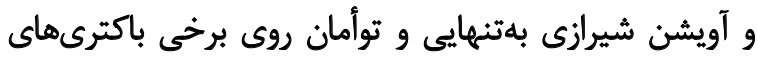

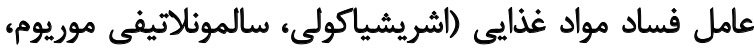

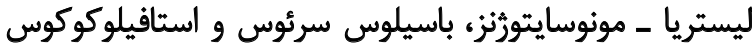

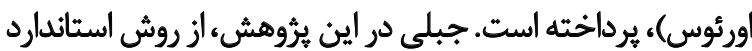

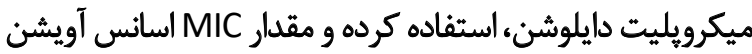

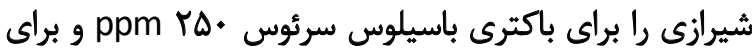

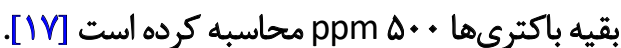
متوسل و همكاران در سال سوجـا ، اثر باكتريوسايدال آويشن

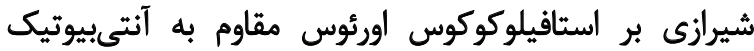

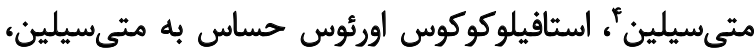

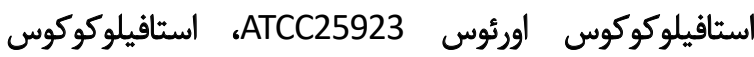

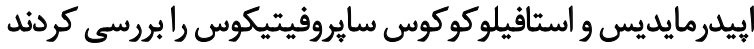

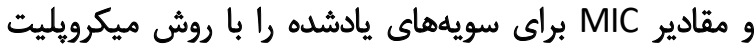

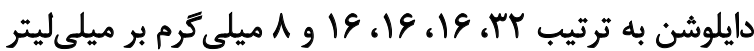

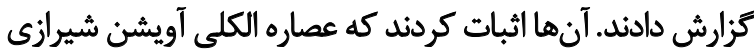

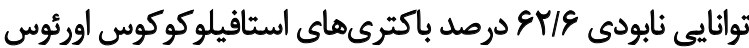

4. Methicillin-resistant Staphylococcus aureus (MRSA)
ليجيدى داشته و باعث نابودى مواد غذايى، ايجاد زمينه رشد

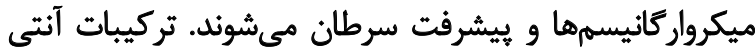

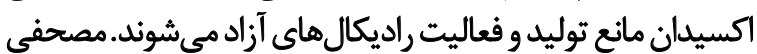

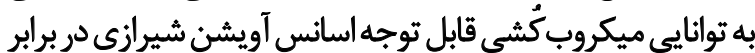

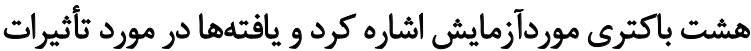

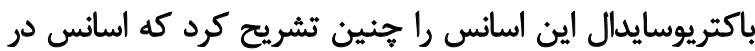

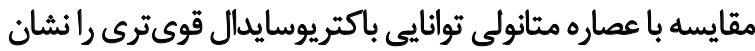

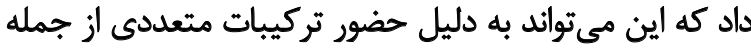

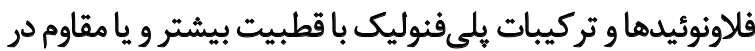

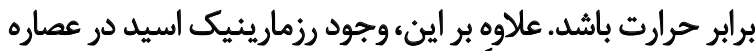

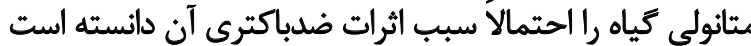

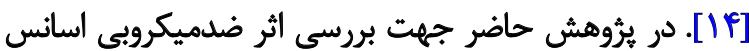

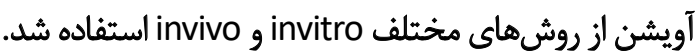

با توجه به ضرورت نفوذ اسانس به درون بافت مشبك آتار

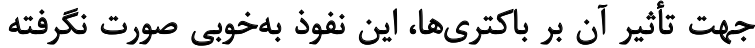

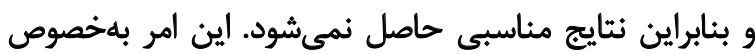

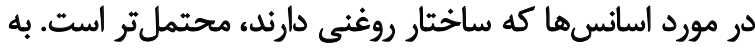

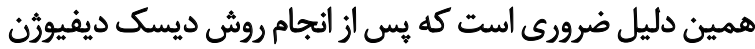

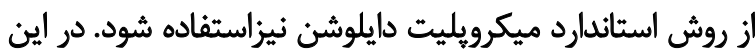

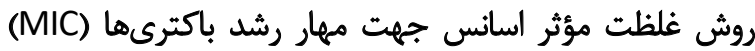

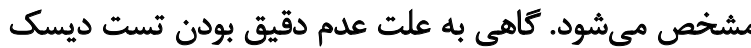

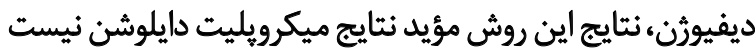

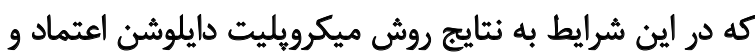

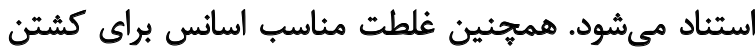

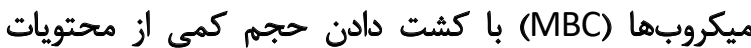

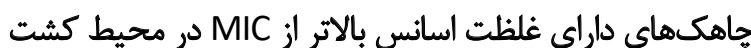

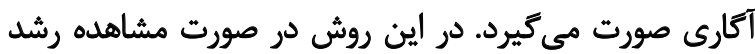

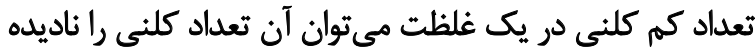

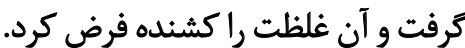

يزدى و همكاران در يروهشى تأثير اسانس كياهى، Zataria Eucalyp- و multiflora Boiss. ، Myrtus communis L tus officinalis

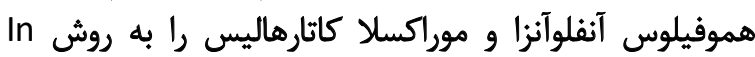

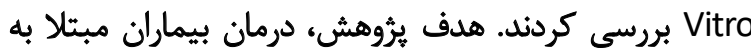

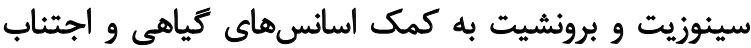
از مصرف أنتىبيوتيك بود. در تست ديسك دين ديفيورئن مشخي

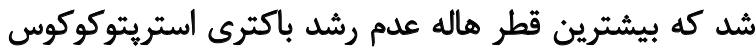

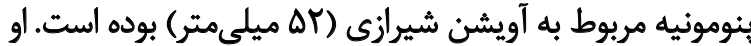

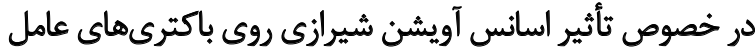

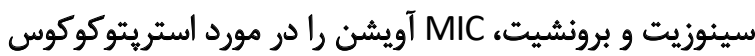

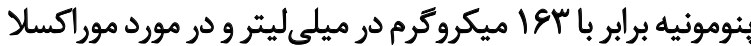

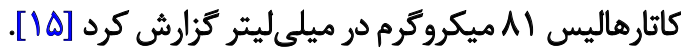
صفرى و همكاران، در بثوهشى روى تأثير تعدادى از 
خود نشان داد و در غلظت كمترى از آن كشته شد. مى توان جمعبندى نمودباكترى استافيلوكوكوس إييدرميديس

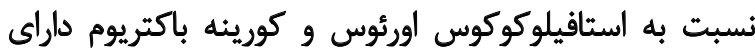

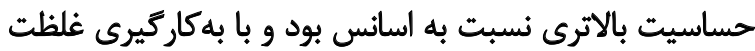

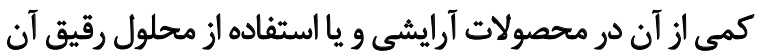
بلهرعت نابود مي ان مشود.

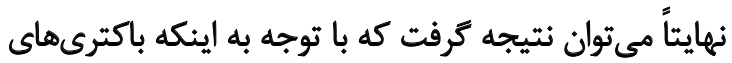

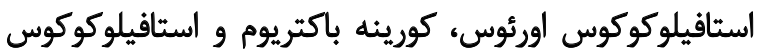

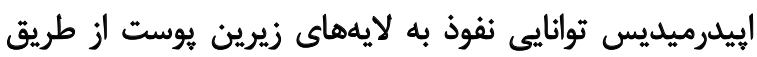

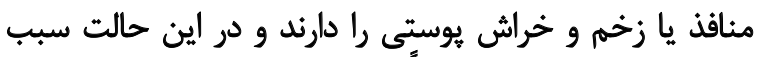

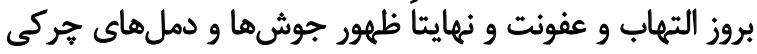

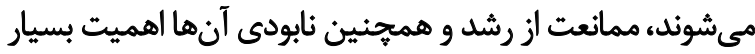

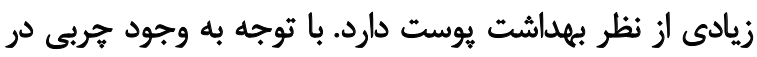

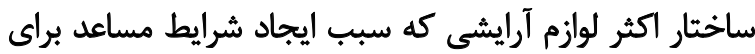

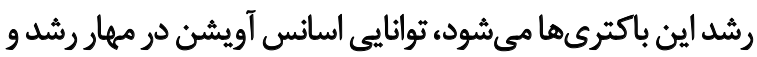

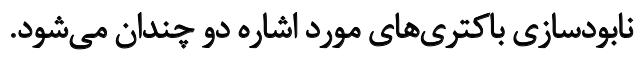

\section{عيرامون حفظ سلامت با استفاده از اسانس آويشن شيرازى و}

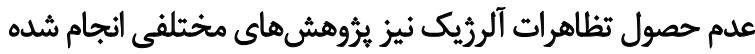

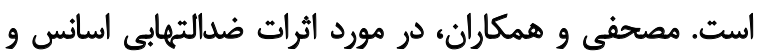

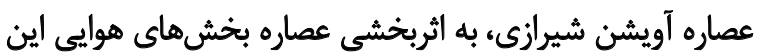

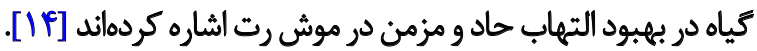
بررسى اثر اسانس رقيق آويشن بر باكترىهاي مورداستفاده

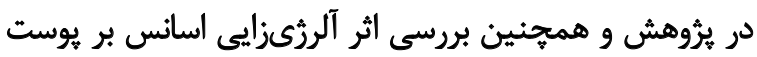

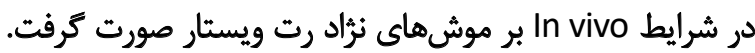

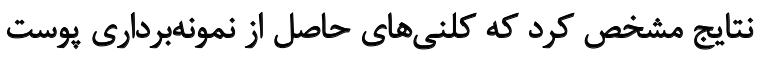

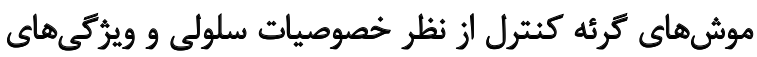

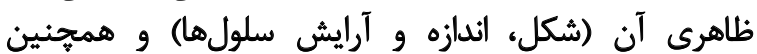

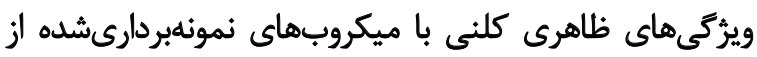

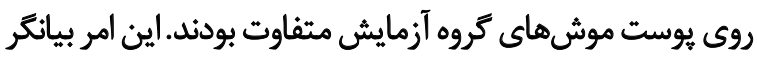

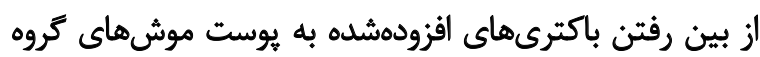

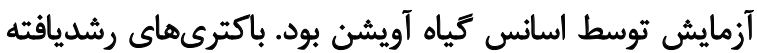

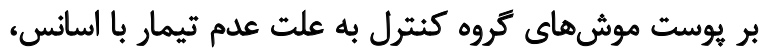

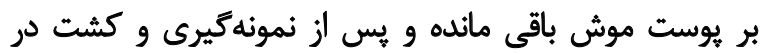

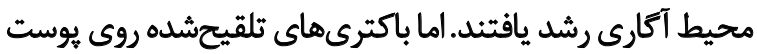

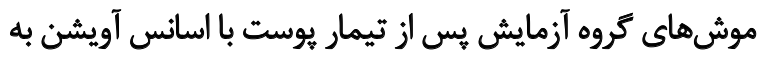

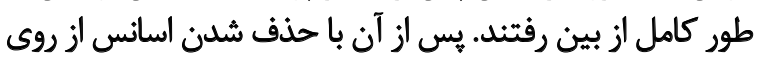

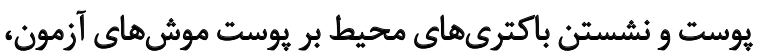
باكترى هاى محيطى امكان رشد يافتند.

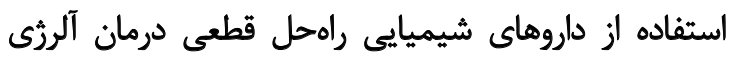

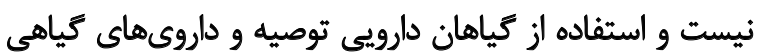

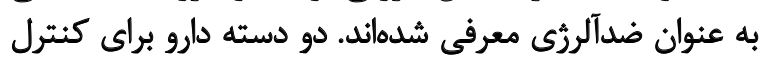

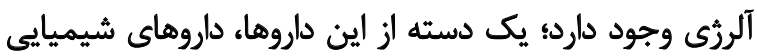

مقاوم به متى سيلين (MRSA) رادارد و حداقل غلظت باكترى كُشى إنى استاف اورئوس حساس به متىسيلين، استاف اورئوس

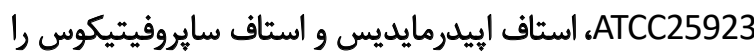

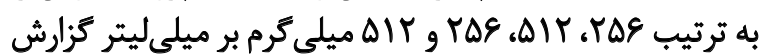

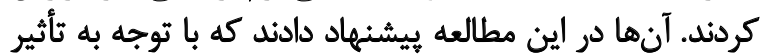

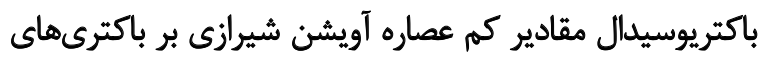

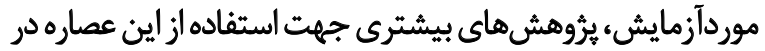

ضمادهاي يوستى با هدف باكترىزدايى انجام شود [1/1].

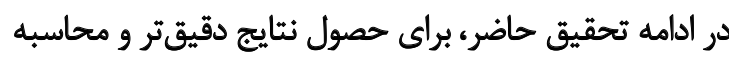

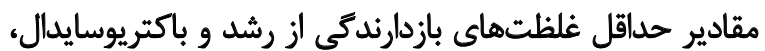

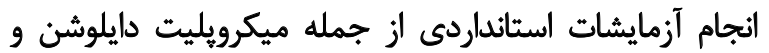
كشتهاى تكميلى انجام شد.

نتايج ميكرويليت دايلوشن ارائهشده در اين بثروهش (جدول

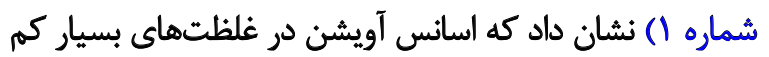

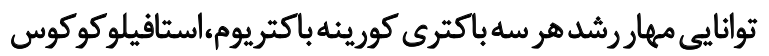

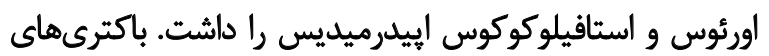

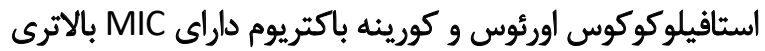

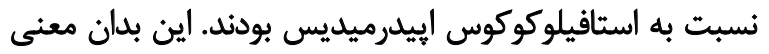

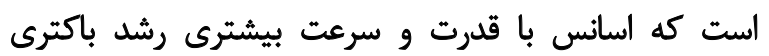
استافيلوكوكوس اييدرميديس را مهار كرده است وند

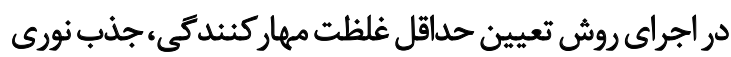

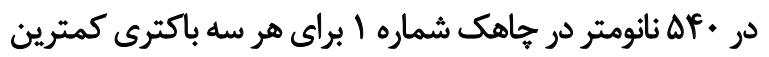

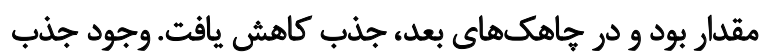

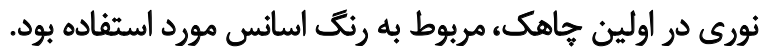

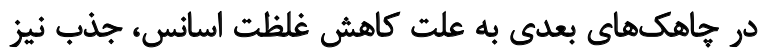

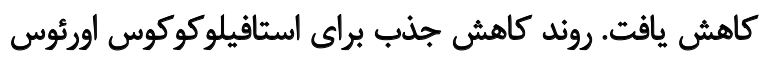

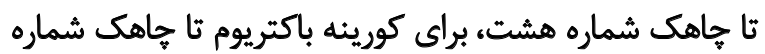

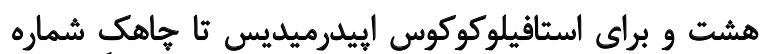

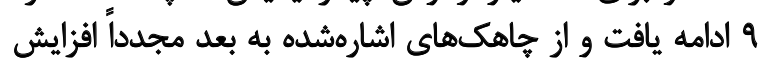

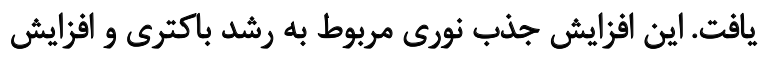

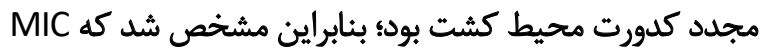

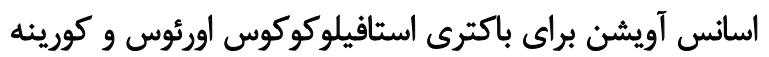

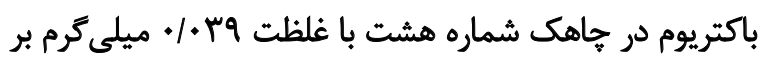

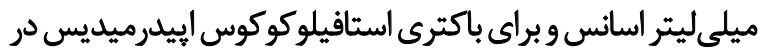

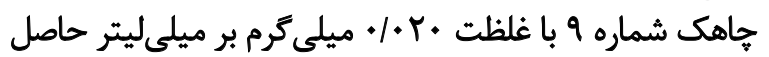

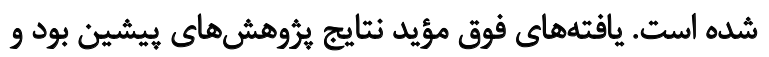

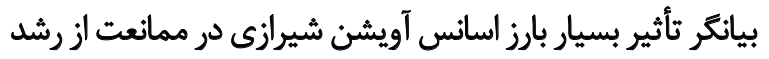

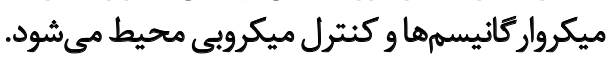
در ادامه تحقيق مقدار حداقل غلظت كشيندكى (MBC) اسانس

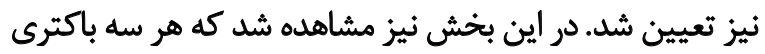

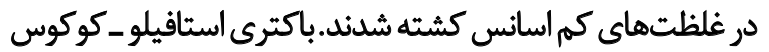

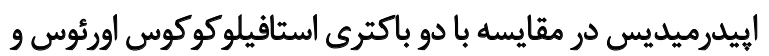

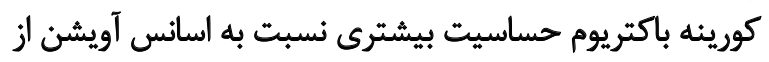




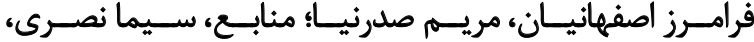

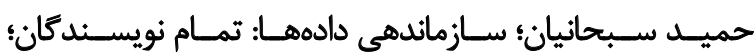

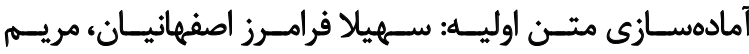

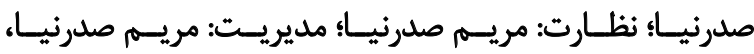

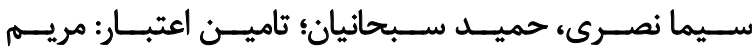
صدرنيـا، سـيما نصــرى، حميــد ســبحانيان.

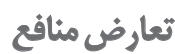

بنابر اظهار نويسندكان اين مقاله تعارض منافع ندارد.

$$
\text { تشيكر وقبدروائي }
$$

بدينوسيله از معاونت بُروهشى دانشَاه يِام نور جهت همكارى در انجام اين يُؤوهش قدردانى مىشودي
و آنتى هيستامينها هستند كه هيستامينهاى خون را خنثى

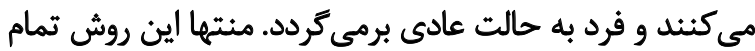

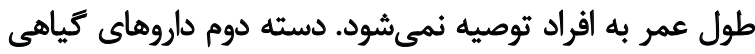

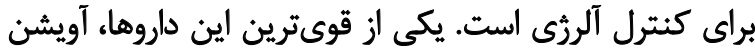

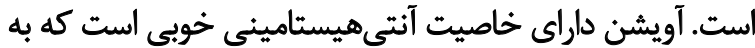

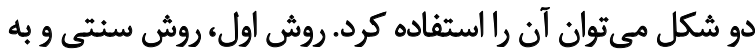

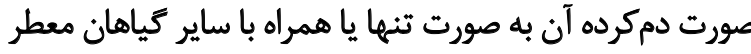

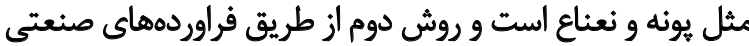

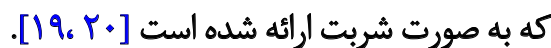

نتايج تحقيق حاضر در خصوص عدم آلرزىزايى اسانس

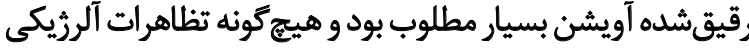
روى يوست رتها مشاهده نشد.

با توجه به تركيبات موجود در كياه دارويى آويشن شيرازى، آني،

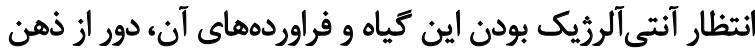

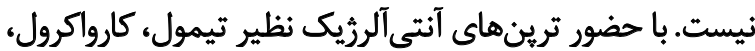

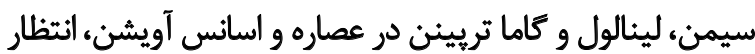

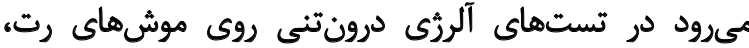

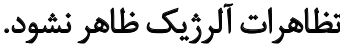

تيجيةكيرى

نتايج يروهش انجامشده، قدرت ميكروبكُشى اسانس آويشن شيرازى را بر باكترىهاي انتخابشده، اثبات كرد. همجئين

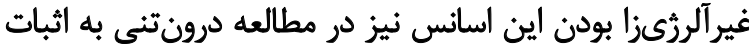

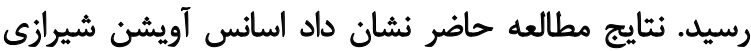

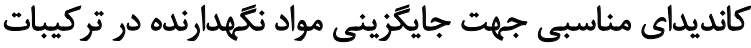

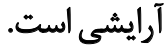

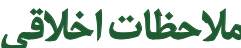

ييروى از أصول اخلاق يثوهش

اين مطالعه با كد رهكيرى 2545562 و در كميته ملى اخلاق

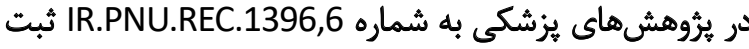

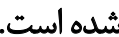

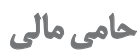

اين مقاله بركرفته از قاياننامه كارشناسى ارشد نويسنده اول

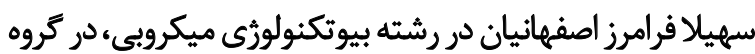
زيستشناسى دانشكاه يُيام نور است.

مشار كت نويسندكان

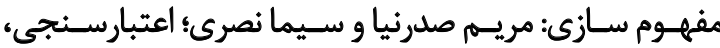

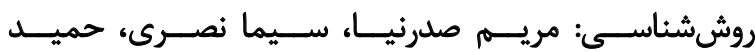

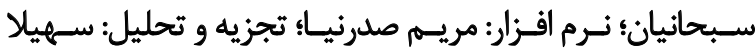




\section{References}

[1] Nagoor Meeran MF, Javed H, Al Taee H, Azimullah Sh, Ojha SK. Pharmacological properties and molecular mechanisms of thymol: Prospects for its therapeutic potential and pharmaceutical development. Frontiers in Pharmacology. 2017; 8:380. [DOI:10.3389/fphar.2017.00380] [PMID] [PMCID]

[2] Martins IM, Rodrigues SN, Barreiro F, Rodrigues AE. Microencapsulation of thyme oil by coacervation. Journal of Microencapsulation. 2009; 26(8):667-75. [DOI:10.3109/02652040802646599] [PMID]

[3] Lambert RJW, Skandamis PN, Coote PJ, Nychas GJE. A study of the minimum inhibitory concentration and mode of action of oregano essential oil, thymol and carvacrol. Journal of Applied Microbiology. 2001; 91(3):453-62. [DOI:10.1046/j.1365-2672.2001.01428.x] [PMID]

[4] Ghazvini K, Safdari H. [Bacterial contamination of eye cosmetics before and after use in Iran (Persian)]. Research in Medicine. 2007; 31(2):15962. http://pejouhesh.sbmu.ac.ir/article-1-394-en.html

[5] Morse L, Williams HL, Grenn FP, Eldridge EE, Rotta JR. Septicemia due to Klebsiella pneumoniae originating from a hand-cream dispenser. The New England Journal of Medicine. 1967; 277(9):472-3. [DOI:10.1056/ NEJM196708312770906] [PMID]

[6] Campana R, Scesa C, Patrone V, Vittoria E, Baffone W. Microbiological study of cosmetic products during their use by consumers: Health risk and efficacy of preservative systems. Letters in Applied Microbiology. 2006; 43(3):301-6. [DOI:10.1111/j.1472-765X.2006.01952.x] [PMID]

[7] Güven N, Kaynak Onurdağ F. [Investigation of antimicrobial and antibiofilm effects of some preservatives used in drugs, cosmetics and food products (Turkish)]. Mikrobiyoloji Bülteni. 2014; 48(1):94-105. [PMID]

[8] Halla N, Fernandes IP, Heleno SA, Costa P, Boucherit-Otmani Z, Boucherit $\mathrm{K}$, et al. Cosmetics preservation: A review on present strategies. Molecules. 2018; 23(7):1571. [DOI:10.3390/molecules23071571] [PMID] [PMCID]

[9] Kizhedath A, Wilkinson S, Glassey J. Assessment of hepatotoxicity and dermal toxicity of butyl paraben and methyl paraben using HepG2 and HDFn in vitro models. Toxicology in Vitro. 2019; 55:108-15. [DOI:10.1016/j.tiv.2018.12.007] [PMID]

[10] Lundov MD, Johansen JD, Zachariae C, Moesby L. Low-level efficacy of cosmetic preservatives. International Journal of Cosmetic Science. 2011; 33(2):190-6. [DOI:10.1111/j.1468-2494.2010.00619.x] [PMID]

[11] Cogen AL, Nizet V, Gallo RL. Skin microbiota: A source of disease or defence? The British Journal of Dermatology. 2008; 158(3):442-55. [DOI:10.1111/j.1365-2133.2008.08437.x] [PMID] [PMCID]

[12] Ali B, Al-Wabel NA, Shams S, Ahamad A, Khan SA, Anwar A. Essential oils used in aromatherapy: A systemic review. Asian Pacific Journal of Tropical Biomedicine. 2015; 5(8):601-11. [DOI:10.1016/j.apjtb.2015.05.007]

[13] Ashtaral Nakhai L, Mohammadirad A, Yasa N, Minaie B, Nikfar Sh, Ghazanfari Gh, et al. Benefits of Zataria multiflora Boiss in experimental model of mouse inflammatory bowel disease. Evidence-Based Complementary and Alternative Medicine. 2007; 4(1):43-50. [DOI:10.1093/ ecam/nel051] [PMID] [PMCID]

[14] Moshafi MH, Mansouri Sh, Sharififar F, Khoshnoodi M. [Antibacterial and antioxidant effects of the essential oil and extract of Zataria multiflora Boiss (Persian)]. Journal of Kerman University of Medical Sciences. 2007; 14(1):33-43. https://www.sid.ir/fa/journal/ViewPaper. aspx?ID=57685
[15] Yazdi MH, Pourmand MR, Bayat M, Shahinjafari A. [In vitro antimicrobial effects of Zataria multiflora Boiss., Myrtus communis L. and Eucalyptus officinalis against Streptococcus pneumoniae, Moraxella catarrhalis and Haemophilus influenza (Persian)]. Iranian Journal of Medicinal and Aromatic Plants. 2008; 23(4):477-83. https://www.sid.ir/fa/journal/ ViewPaper.aspx?ID=73853

[16] Safari R, Adel M, Monji H, Riyahi Cholicheh H, Nematolahi A. [Evaluation of antibacterial effect some of the endemic herbal essential oils on Streptococcus iniae in invitro (Persian)]. Journal of Aquatic Ecology. 2015; 4(4):33-40. https://www.sid.ir/fa/journal/ViewPaper.aspx?ID=292529

[17] Jebelli Javan A. [Combinational effects of Trachyspermum ammi and Zataria multiflora Boiss essential oils on some pathogenic food-borne bacteria (Persian)]. Koomesh. 2016; 17(2):374-83. http://koomeshjournal.semums.ac.ir/article-1-2779-en.html

[18] Motevasel M, Okhovat MA, Zomorodian K, Farshad Sh. [Antibacterial effect of Zataria multiflora extract on MRSA (Persian)]. Iranian South Medical Journal. 2014; 17(5):900-6. http://ismj.bpums.ac.ir/article1-604-en.html

[19] Ghafourian Boroujerdnia M, Azemi ME, Hemmati AA, Taghian A, Azadmehr A. Immunomodulatory effects of Astragalus gypsicolus hydroalcoholic extract in ovalbumin-induced allergic mice model. Iranian Journal of Allergy, Asthma, and Immunology. 2011; 10(4):281-8. [PMID]

[20] Nikakhlagh S, Rahim F, Hossein Nejad Aryani F, Syahpoush A, Ghafouryan Brougerdnya M, Saki N. Herbal treatment of allergic rhinitis: The use of Nigella sativa. American Journal of Otolaryngology. 2011; 32(5):402-7. [DOI:10.1016/j.amjoto.2010.07.019] [PMID] 